\title{
Influence of comorbid heart disease on dyspnea and health status in patients with COPD - a cohort study
}

This article was published in the following Dove Press journal: International Journal of COPD

\author{
Maaike Giezeman ${ }^{1,2}$ \\ Mikael Hasselgren' \\ Karin Lisspers ${ }^{3}$ \\ Björn Ställberg ${ }^{3}$ \\ Scott Montgomery ${ }^{4-6}$ \\ Christer Janson ${ }^{7}$ \\ Josefin Sundh ${ }^{8}$
}

'School of Medical Sciences, Örebro University, Örebro, Sweden; ${ }^{2}$ Centre for Clinical Research, County Council of Värmland, Karlstad, Sweden; ${ }^{3}$ Department of Public Health and Caring Sciences, Family Medicine and Preventive Medicine, Uppsala University, Uppsala, Sweden; ${ }^{4}$ Clinical Epidemiology and Biostatistics, Örebro University, Örebro, Sweden; ${ }^{5}$ Clinical Epidemiology Unit, Department of Medicine, Karolinska Institutet, Stockholm, Sweden; ${ }^{6}$ Department of Epidemiology and Public Health, University College, London, UK; ${ }^{7}$ Department of Medical Sciences, Respiratory, Allergy and Sleep Research, Uppsala University, Uppsala, Sweden; ${ }^{8}$ Department of Respiratory Medicine, School of Medical Sciences, Örebro University, Örebro, Sweden
Correspondence: Maaike Giezeman Centre for Clinical Research, County Council of Värmland, Centralsjukhuset, Hus 73 plan 3, 65I 85 Karlstad, Sweden Tel +46730253339

Email maaike.giezeman@liv.se
Purpose: The aim of this study was to examine the changing influence over time of comorbid heart disease on symptoms and health status in patients with COPD.

Patients and methods: This is a prospective cohort study of 495 COPD patients with a baseline in 2005 and follow-up in 2012. The study population was divided into three groups: patients without heart disease (no-HD), those diagnosed with heart disease during the study period (new-HD) and those with heart disease at baseline (HD). Symptoms were measured using the mMRC. Health status was measured using the Clinical COPD Questionnaire (CCQ) and the COPD Assessment Test (CAT; only available in 2012). Logistic regression with mMRC $\geq 2$ and linear regression with CCQ and CAT scores in 2012 as dependent variables were performed unadjusted, adjusted for potential confounders, and additionally adjusted for baseline mMRC, respectively, CCQ scores.

Results: Mean mMRC worsened from 2005 to 2012 as follows: for the no-HD group from $1.8( \pm 1.3)$ to $2.0( \pm 1.4),(P=0.003)$, for new-HD from $2.2( \pm 1.3)$ to $2.4( \pm 1.4),(P=0.16)$, and for HD from $2.2( \pm 1.3)$ to $2.5( \pm 1.4),(P=0.03)$. In logistic regression adjusted for potential confounding factors, HD (OR 1.71; 95\% CI: 1.03-2.86) was associated with mMRC $\geq 2$. Health status worsened from mean CCQ as follows: for no-HD from $1.9( \pm 1.2)$ to $2.1( \pm 1.3)$ with $(P=0.01)$, for new-HD from $2.3( \pm 1.5)$ to $2.6( \pm 1.6)$ with $(P=0.07)$, and for HD from 2.4 $( \pm 1.1)$ to $2.5( \pm 1.2)$ with $(P=0.57)$. In linear regression adjusted for potential confounders, HD (regression coefficient 0.12 ; 95\% CI: $0.04-5.91)$ and new-HD $(0.15 ; 0.89-5.92)$ were associated with higher CAT scores. In CCQ functional state domain, new-HD $(0.14 ; 0.18-1.16)$ and HD $(0.12 ; 0.04-0.92)$ were associated with higher scores. After additional correction for baseline $\mathrm{mMRC}$ and CCQ, no statistically significant associations were found.

Conclusion: Heart disease contributes to lower health status and higher symptom burden in COPD but does not accelerate the worsening over time.

Keywords: COPD Assessment Test, CAT, Clinical COPD Questionnaire, CCQ, modified Medical Research Council dyspnea score, $\mathrm{mMRC}$, ischemic heart disease, heart failure

\section{Introduction}

COPD is a common disease causing significant morbidity and mortality worldwide. ${ }^{1}$ Symptom burden and health status are important patient-related outcomes in the management of patients with COPD. A multidimensional assessment of disease severity, including $\mathrm{FEV}_{1}$, health status and exacerbation frequency, is advocated by the Global Initiative for Obstructive Lung Disease (GOLD). ${ }^{2}$ For the measurement of dyspnea symptom burden, the use of mMRC is widespread. ${ }^{3}$ For the assessment of health status, GOLD recommends the COPD Assessment Test (CAT) that was developed in $2009 .{ }^{4}$ 
The Clinical COPD Questionnaire (CCQ) is considered by GOLD as an instrument with equal qualities. ${ }^{5}$ Since it has been in use since 2003, it is more suitable for longitudinal analysis.

COPD is associated with a high prevalence of comorbid conditions, and COPD patients have a two to five times higher risk of developing heart disease. ${ }^{6}$ The prevalence of ischemic heart disease is estimated to be $22 \%-33 \%$ and chronic heart failure $14 \%-24 \%$ in patients with COPD. ${ }^{7-9}$ The observed association between COPD and heart disease can be explained partly by shared risk factors such as smoking, age, and inactivity. However, it is also thought that a systemic inflammatory process related to COPD may independently increase the risk of heart disease. ${ }^{10}$

Comorbid heart disease has, in cross-sectional studies, been shown to be associated with lower health status in patients with COPD. ${ }^{11-13}$ It has also been reported that disease-specific health status worsens over time in patients with COPD, ${ }^{14-16}$ although this could not be shown with a general instrument in a group of patients with low disease severity. ${ }^{17}$ The aim of this study was to examine the changing influence over a 7-year follow-up period of comorbid heart disease on symptoms of dyspnea measured by mMRC and health status measured by CCQ and CAT in patients with COPD.

\section{Patients and methods Data collection}

The data were obtained from the PRAXIS study cohort that was created in 2005 with a follow-up in $2012 .{ }^{14}$ The PRAXIS study is based on the data from 14 hospitals and 56 primary health care centers in seven counties in mid-Sweden. A total of 1,548 patients were randomly selected from lists with patients aged 34-75 years with an ICD 10 diagnosis code J44 for COPD recorded in their medical records during 2000-2003. The random selection was made from the respective health care unit's diagnosis list by a research nurse, using an Internet-based program (https://www.random.org/). A patient questionnaire was sent to these patients. In 2012, all patients who were still alive received a similar questionnaire as in 2005. A total of 561 patients returned both the baseline and the follow-up questionnaires (Figure 1).

\section{Patient characteristics and measures}

The medical records were reviewed at baseline for the period 2000-2003 and again at follow-up for the period 2004-2012. The record review produced information on a doctor's diagnosis of heart disease, hypertension, depression,

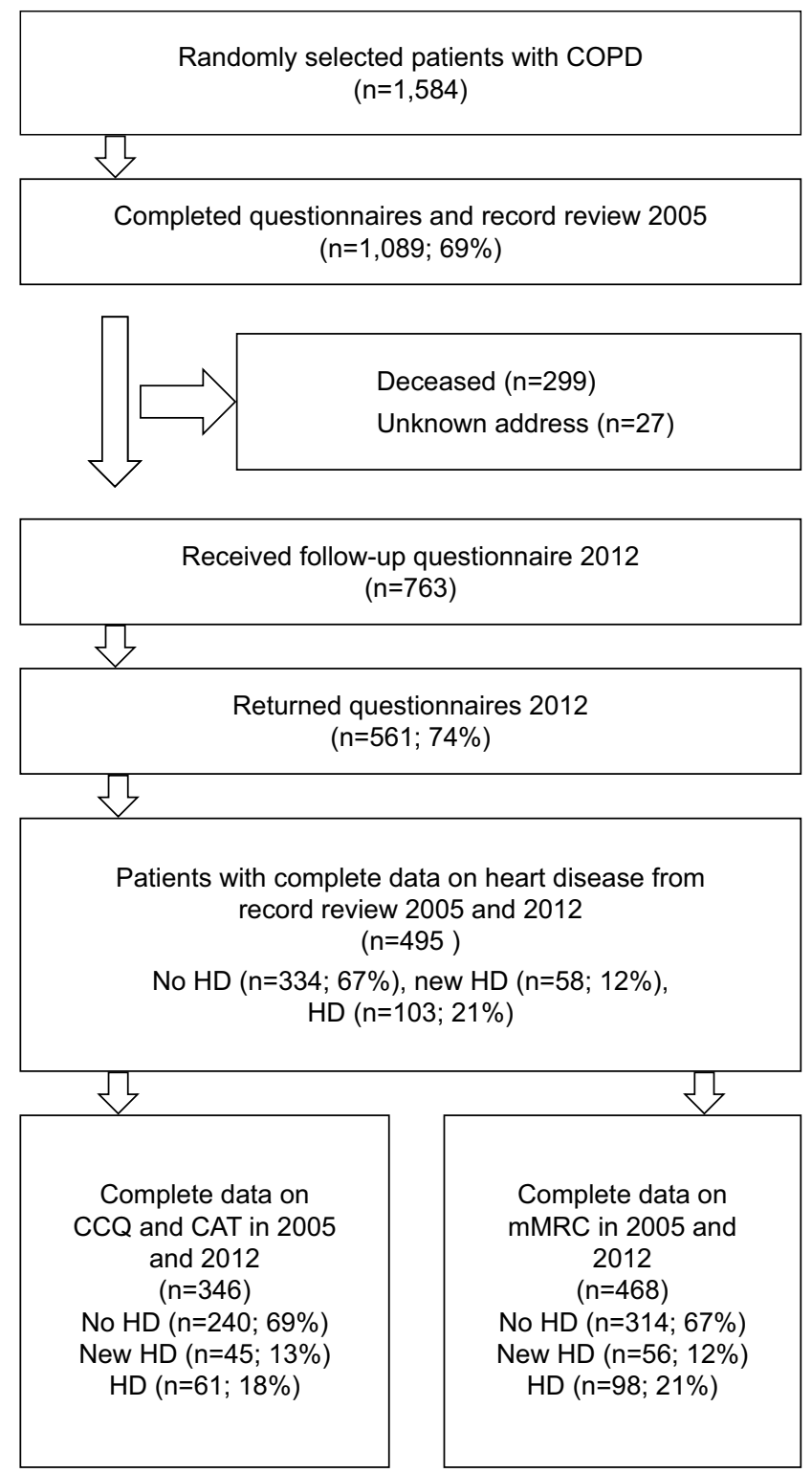

Figure I Flow chart patient selection.

Notes: HD = COPD patients with a heart disease diagnosis at baseline. New $H D=$ COPD patients with heart disease diagnosed between 2003 and 2012. No $\mathrm{HD}=\mathrm{COPD}$ patients without heart disease.

Abbreviations: CAT, COPD Assessment Test; CCQ, Clinical COPD Questionnaire; $\mathrm{HD}$, heart disease.

diabetes and data on lung function. Heart disease was defined as a doctor's diagnosis of ischemic heart disease or heart failure registered in the medical records. The study population was divided into three groups: COPD patients without a diagnosis of heart disease (no HD), those who were diagnosed with heart disease during the study period 2003-2012 (new HD) and those who had a heart disease diagnosis at the start of the study 2003 (HD). In patients where spirometry data were available at baseline $(n=216)$, their disease was graded based on the $\mathrm{FEV}_{1}$ expressed as a percentage of the European Community for Steel and Coal reference values (FEV ${ }_{1} \%$ pred). ${ }^{18}$ 
The questionnaires provided information on age, sex, smoking status, level of education, exacerbations in the previous 6 months, height, weight, mMRC and CCQ. In addition, the questionnaire in 2012 included CAT.

For patient characteristics, baseline data from 2005 were used. Age was categorized into three groups: $\leq 60$ years, 61-70 years, and $>70$ years. Smoking status was categorized into "current daily smoking" and "not current daily smoking". The latter group included patients who never smoked, had stopped smoking or smoked occasionally. The dichotomous educational variable identified the most highly educated group as those who had continued full-time education for at least 2 years beyond the Swedish compulsory school period of 9 years. An exacerbation was defined as an emergency visit or the need for a course of oral steroids during the previous 6 months due to worsening of COPD symptoms. Height and weight were used to calculate body mass index (BMI) in $\mathrm{kg} / \mathrm{m}^{2}$. Underweight was defined as a BMI $<20$, normal weight as a $\mathrm{BMI} \geq 20$ and $<25$, overweight as $\mathrm{BMI} \geq 25$ and $<30$ and obesity as BMI $\geq 30$.

\section{Dyspnea}

Dyspnea was measured by the $\mathrm{mMRC}$, where a score of 0 or 1 corresponds to no dyspnea or dyspnea on strenuous exercise, and scores of 2 and more denote increasing limitation of activity due to dyspnea in daily life. The scale has been validated and is frequently used in clinical and research settings. ${ }^{3}$ For regression analysis, the mMRC score was dichotomized to low burden of dyspnea (mMRC score of 0 and 1) and patients high burden of dyspnea (score of 2-4) according to GOLD. ${ }^{2}$

\section{Health status}

The CCQ includes ten items about the patients' health the previous week, distributed over three domains: symptoms, mental state and functional state. ${ }^{19}$ The symptoms domain contains questions on dyspnea, cough and phlegm; the mental state describes the feelings of depression and concerns about breathing or getting worse; and the functional state assesses the limitations in different activities of daily life due to lung disease. Answers are given on 7-point scale from 0 to 6 . The main outcome is the total mean CCQ value; a separate mean score for each domain can also be calculated. A higher score indicates lower health status. The minimal clinically important difference for CCQ is established to be 0.4 units..$^{20}$ The CAT includes eight items about the patients' experience of cough, mucus production, chest tightness, dyspnea on exercise, limitation of activities at home, sense of confidence about leaving the house, sleep and energy level. ${ }^{4}$ The patient scores the symptoms on a 6-point scale from 0 to 5 . A high score indicates lower health status. The main outcome measure is the sum of the scores, varying between 0 and 40 . The minimal clinically important difference for CAT has been suggested to be 2-3 units. ${ }^{20}$ The health status instruments, CCQ and CAT, correlate well with St Georges Respiratory Questionnaire (SGRQ) and with each other and can be used as equivalents for measuring health status. ${ }^{4,5,21}$

\section{Statistical analyses}

Categorical data were expressed using frequencies and percentages, while continuous data were expressed using mean values and SDs. The chi-squared test and Student's $t$-test were used to examine the differences in characteristics between patients without heart disease (no HD) and patients with heart disease at baseline (HD) and those who were diagnosed with heart disease during the study period (new HD). Logistic regression analysis used the dichotomous mMRC score $\geq 2$ as the dependent variable. Heart disease in 2012 (three groups - no HD, new HD and HD), and the potential confounding factors of age, sex, level of education, smoking status, presence of exacerbations in the previous 6 months, diabetes, hypertension, depression, and BMI at baseline were used as independent variables. Heart disease, age and BMI were modeled as a series of binary dummy variables. Linear regression analysis used mean CCQ score and total CAT score in 2012 as dependent variables. The same independent variables as in the analysis of mMRC were investigated. All the analyses were performed as unadjusted, adjusted and additionally adjusted for the value of the outcome measure at baseline. In adjusted analysis, only the variables with a statistically significant association $(P<0.05)$ in unadjusted analysis were included. As CAT was not available in 2005, the mean CCQ score at baseline was used as replacement for CAT at baseline. Stratification and multiplicative interaction analyses were used to investigate potential effect modification by sex and different age groups ( $\leq 60,61-70$ and $>70$ years). The main analyses for mMRC, CCQ and CAT were all repeated in the subgroup with available spirometry data, with additional adjustment for the $\mathrm{FEV}_{1}$ \%pred groups GOLD I-IV. ${ }^{2}$ A $P$-value of $<0.05$ was considered significant. SPSS version 21 (IBM Corporation, Armonk, NY, USA) was used.

\section{Ethics}

The study was approved by the regional ethical review board of Uppsala University (Dnr 2004:M-445 and Dnr 2010/090). Written informed consent was obtained from all participating patients. 


\section{Results}

\section{Patient characteristics}

Patient characteristics at baseline are shown in Table 1. COPD patients with comorbid heart disease during the whole study were more often male, older, lower educated and selected from the hospital care population, than those without heart disease. The group with incident heart disease was older and had relatively less daily smokers compared to those without heart disease. The number of COPD patients with comorbid heart disease for each patient sample and the total group is presented in Figure 2.

Between baseline and follow-up, 299 patients died, and another 229 patients did not complete the second questionnaire due to other reasons. An attrition analysis showed that the deceased patients more often were from the oldest age group $(P<0.001)$ and more often had comorbid heart disease

Table I Patient characteristics in 2005 by HD group in 2012

\begin{tabular}{|c|c|c|c|c|c|c|}
\hline Baseline characteristics, 2005 & $\begin{array}{l}\text { All patients, } \\
\text { n (\%) }\end{array}$ & $\begin{array}{l}\text { No HD, } \\
\text { n (\%) }\end{array}$ & $\begin{array}{l}\text { New HD, } \\
\text { n (\%) }\end{array}$ & $P$-value & HD, n (\%) & $P$-value \\
\hline Number of patients & 495 & $334(67)$ & $58(12)$ & & $103(2 I)$ & \\
\hline Sex & & & & 0.17 & & $<0.001$ \\
\hline Male & $207(42)$ & $118(35)$ & $26(45)$ & & $63(6 \mathrm{I})$ & \\
\hline Female & $288(58)$ & $216(65)$ & $32(55)$ & & $40(39)$ & \\
\hline Age groups (years) & & & & 0.002 & & $<0.001$ \\
\hline$\leq 60$ & $143(35)$ & $118(35)$ & $7(12)$ & & $18(18)$ & \\
\hline $61-70$ & $160(48)$ & $160(48)$ & $39(67)$ & & $54(52)$ & \\
\hline$>70$ & $56(17)$ & $56(17)$ & $12(21)$ & & $31(30)$ & \\
\hline Level of education $(n=488)$ & & & & 0.73 & & 0.02 \\
\hline Low & $322(66)$ & $207(63)$ & $38(66)$ & & $77(75)$ & \\
\hline High & $166(34)$ & $121(37)$ & $20(34)$ & & $25(25)$ & \\
\hline Level of care & & & & 0.41 & & $<0.001$ \\
\hline Hospital care & $90(18)$ & $44(13)$ & $10(17)$ & & $36(35)$ & \\
\hline Primary care & $405(82)$ & $290(87)$ & $48(82)$ & & $67(65)$ & \\
\hline Current daily smoking & & & & 0.01 & & 0.22 \\
\hline No & $363(73)$ & $232(70)$ & $53(91)$ & & $78(76)$ & \\
\hline Yes & $132(27)$ & $102(30)$ & $5(9)$ & & $25(24)$ & \\
\hline FEV,\%pred $(n=2 \mid 6)$ & & & & 0.47 & & 0.79 \\
\hline$\geq 80$ & $54(21)$ & $38(23)$ & $4(15)$ & & $12(20)$ & \\
\hline $50-79$ & $132(52)$ & $89(53)$ & $13(50)$ & & $30(5 \mathrm{I})$ & \\
\hline$<50$ & $67(27)$ & $41(24)$ & $9(35)$ & & $17(29)$ & \\
\hline BMI $\left(\mathrm{kg} / \mathrm{m}^{2} ; \mathrm{n}=480\right)$ & & & & 0.21 & & 0.25 \\
\hline Underweight $(<20)$ & $40(8)$ & $29(9)$ & $2(3)$ & & $9(9)$ & \\
\hline Normal weight $(\geq 20,<25)$ & $168(35)$ & $116(36)$ & $25(44)$ & & $27(27)$ & \\
\hline Overweight $(\geq 25, \leq 30)$ & $173(36)$ & $118(37)$ & $16(28)$ & & $39(39)$ & \\
\hline Obesity $(>30)$ & $99(21)$ & $59(18)$ & $14(25)$ & & $26(26)$ & \\
\hline Depression & $57(12)$ & $42(13)$ & $7(12)$ & 0.91 & $8(8)$ & 0.18 \\
\hline Diabetes & $50(10)$ & $29(9)$ & $7(12)$ & 0.41 & $14(14)$ & 0.14 \\
\hline Hypertension & $124(25)$ & $78(23)$ & $16(28)$ & 0.49 & $30(29)$ & 0.24 \\
\hline Exacerbation in the previous 6 months & & & & 0.84 & & 0.88 \\
\hline No exacerbation & $310(65)$ & $208(65)$ & $37(64)$ & & $65(64)$ & \\
\hline$\geq I$ exacerbation & $166(35)$ & III (35) & $21(36)$ & & $101(36)$ & \\
\hline
\end{tabular}

Notes: No HD = COPD patients without heart disease; new HD = patients diagnosed with heart disease between 2003 and 20I2; HD = COPD patients with heart disease at baseline. P-values with no HD as reference. Exacerbation was defined as an unplanned health care visit or course of oral steroids.

Abbreviation: BMI, body mass index. 


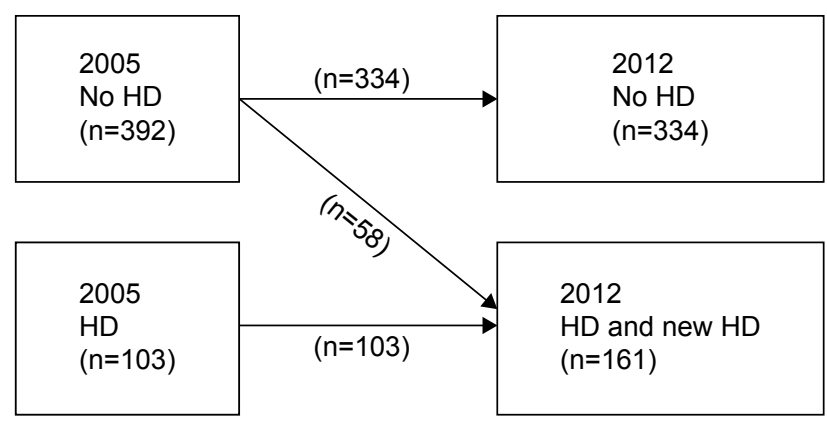

Figure 2 Number of COPD patients in the whole study group with comorbid heart disease in 2003 and 2012.

Notes: $\mathrm{HD}=\mathrm{COPD}$ patients with heart disease at baseline. New HD = patients diagnosed with heart disease between 2003 and 2012. No HD = COPD patients without heart disease.

$(P<0.001)$. There were no statistically significant differences between non-responders and responders among patients alive in 2012 (data not shown).

\section{Dyspnea}

At baseline, mMRC scores were significantly higher for the group with heart disease at baseline (HD) and for those who later, during the study, developed heart disease (new HD) compared to those without a heart disease diagnosis (no HD) (Table 2). There was a significant increase in dyspnea symptoms during the study period for the groups with and without heart disease during the whole study period, but not for the new HD group (Figure 3). The results of the logistic regression analysis for $\mathrm{mMRC}$ are presented in in Table 3. Comorbid heart disease during the whole study period (HD) was an independent statistically significant factor for a higher mMRC score at follow-up. After correction for baseline mMRC, no significant associations were found. Interaction analysis showed no effect modification by sex or age (data not shown). In the subgroup with available spirometry data, heart disease had no associations with the mMRC score (data not shown).

\section{Health status}

At baseline, CCQ scores were significantly higher for the group with HD and group with new HD (Table 2). Between 2005 and 2012 there was a statistically significant worsening of the mean CCQ, the mean CCQ symptoms, and mean CCQ

Table 2 Symptoms and health status 2005 and 2012

\begin{tabular}{|c|c|c|c|c|c|c|}
\hline & $\begin{array}{l}\text { All patients, } \\
\text { n (\%) }\end{array}$ & $\begin{array}{l}\text { No HD, } \\
\text { n (\%) }\end{array}$ & $\begin{array}{l}\text { New HD, } \\
\text { n (\%) }\end{array}$ & $P$-value & $\begin{array}{l}\text { HD, } \\
\text { n (\%) }\end{array}$ & $P$-value \\
\hline \multicolumn{7}{|l|}{$\mathrm{mMRC} 2005^{\mathrm{a}}$} \\
\hline 0 & $53(11)$ & $39(12)$ & $5(9)$ & Ref & $9(9)$ & Ref \\
\hline 1 & $168(36)$ & $124(38)$ & $17(29)$ & 0.10 & $28(29)$ & 0.96 \\
\hline 2 & $83(18)$ & $54(17)$ & $12(2 I)$ & 0.34 & $17(17)$ & 0.50 \\
\hline 3 & $79(17)$ & $46(15)$ & $10(18)$ & 0.37 & $23(24)$ & 0.09 \\
\hline 4 & $85(18)$ & $51(16)$ & $13(23)$ & 0.23 & $2 I(2 I)$ & 0.20 \\
\hline Mean mMRC 2005 (SD) & $2.0(1.3)$ & $\mathrm{I} .8(\mathrm{I} .3)$ & $2.2(1.3)$ & 0.06 & $2.2(\mathrm{I} .3)$ & 0.02 \\
\hline \multicolumn{7}{|l|}{$\mathrm{mMRC} 2012^{\mathrm{a}}$} \\
\hline 0 & $54(12)$ & $40(13)$ & $4(7)$ & Ref & $10(10)$ & Ref \\
\hline 1 & $137(29)$ & $100(32)$ & $16(29)$ & 0.43 & $21(22)$ & 0.68 \\
\hline 2 & $74(16)$ & $52(16)$ & $10(18)$ & 0.30 & $12(12)$ & 0.87 \\
\hline 3 & $78(16)$ & $53(17)$ & $4(7)$ & 0.70 & $2 I(2 I)$ & 0.29 \\
\hline 4 & $125(27)$ & $69(22)$ & $22(39)$ & 0.05 & $34(35)$ & 0.10 \\
\hline Mean mMRC 2012 (SD) & $2.2(1.4)$ & $2.0(1.4)$ & $2.4(1.4)$ & 0.05 & $2.5(1.4)$ & 0.005 \\
\hline Mean CCQ (SD) 2005 & $2.1(1.3)$ & $1.9(1.2)$ & $2.3(1.5)$ & 0.08 & $2.4(\mathrm{I} . \mathrm{I})$ & 0.002 \\
\hline Symptoms & $2.2(1.3)$ & $2.1(1.2)$ & $2.4(1.4)$ & 0.23 & $2.5(1.2)$ & 0.001 \\
\hline Functional state & $2.2(1.9)$ & $1.6(1.3)$ & $2.2(1.7)$ & 0.01 & $2.2(1.3)$ & 0.002 \\
\hline Mental state & $1.8(1.4)$ & $2.1(1.8)$ & $2.3(1.8)$ & 0.58 & $2.2(1.7)$ & 0.20 \\
\hline Mean CCQ (SD) $2012^{\mathrm{b}}$ & $2.2(1.4)$ & $2.1(1.3)$ & $2.6(1.7)$ & 0.04 & $2.5(1.2)$ & 0.02 \\
\hline Symptoms & $2.4(1.4)$ & $2.3(1.3)$ & $2.6(1.6)$ & 0.10 & $2.7(1.1)$ & 0.01 \\
\hline Functional state & $2.1(1.6)$ & $1.9(1.6)$ & $2.6(1.9)$ & 0.01 & $2.2(1.2)$ & 0.01 \\
\hline Mental state & $2.1(1.6)$ & $2.1(1.7)$ & $2.3(2.0)$ & 0.39 & $2.3(1.7)$ & 0.38 \\
\hline CAT $2012^{b}$ & $17(9.0)$ & $15.9(9.1)$ & $19.1(9.2)$ & 0.04 & $19.9(7.6)$ & 0.002 \\
\hline
\end{tabular}

Notes: mMRC, CCQ and CAT scores in 2005 and 2012 for the different groups of COPD patients with and without heart disease. No HD = COPD patients without heart disease. New HD = COPD patients diagnosed with heart disease between 2003 and 2012 . HD = COPD patients with heart disease at baseline. P-values with no HD as reference. ${ }^{a} n=468,{ }^{b} n=346$.

Abbreviations: CAT, COPD Assessment Test; CCQ, Clinical COPD Questionnaire. 


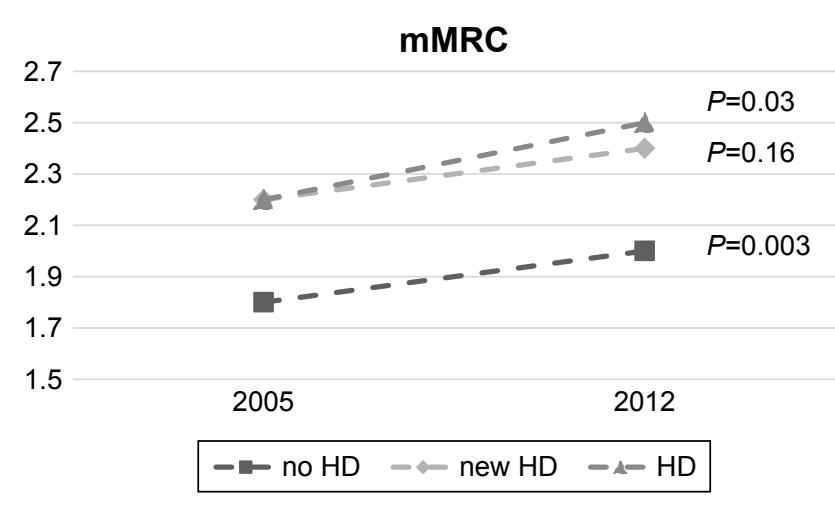

Figure $3 \mathrm{mMRC}$ in 2005 and 2012 in COPD patients without heart disease (no HD), with heart disease diagnosed between 2003 and 2012 (new HD) and with heart disease at baseline (HD).

Notes: $P$-values given for statistical significance of change between 2005 and 2012 value.

functional state in the group of patients with no HD and in the group with new HD. No significant worsening was found in the patients with HD (Figure 4).

The results of the linear regression analyses with the mean CCQ score and total CAT score as dependent variable are presented in Table 3. Both HD and new HD were, statistically, significantly associated with higher CAT and CCQ scores in unadjusted analysis. After adjustment for potential confounding factors, the association with CAT score remained for both HD and new HD, and the association with CCQ remained in the group with new HD. An association for HD was found in the unadjusted analysis of the CCQ symptoms domain and functional state. After adjustment for potential confounders, no association was found for the CCQ symptoms domain, but CCQ functional state showed an association with both HD and new HD. The CCQ mental state domain had no significant associations with heart disease (data not shown). After adjustment for baseline CCQ, no statistically significant associations of heart disease with worse health status, as assessed by CAT or CCQ, total and over all domains, over time were found. The interaction analyses showed no statistically significant effect modification by sex or age for any of the associations (data not shown). In the subgroup with available spirometry data, HD was, statistically, significantly associated with CCQ total, symptoms and functional state domain score and CAT in unadjusted analysis. In the adjusted regression analysis,

Table 3 Regression analyses with CCQ, CAT and $m M R C \geq 2$ in 2012 as dependent variables

\begin{tabular}{|c|c|c|c|c|c|c|}
\hline & $\begin{array}{l}\text { Regression } \\
\text { coefficient } \\
(95 \% \mathrm{Cl})\end{array}$ & $P$-value & $\begin{array}{l}\text { Regression coefficient } \\
(95 \% \mathrm{Cl}) \text {, adjusted for } \\
\text { confounders }\end{array}$ & $P$-value & $\begin{array}{l}\text { Regression coefficient }(95 \% \mathrm{Cl}) \text {, } \\
\text { adjusted for confounders and } \\
\text { baseline } \mathrm{CCQ}\end{array}$ & $P$-value \\
\hline No HD & Ref & Ref & Ref & Ref & Ref & Ref \\
\hline \multicolumn{7}{|c|}{ Linear regression CCQ total } \\
\hline New HD & $0.12(0.04-0.90)$ & 0.03 & $0.12(0.05-0.88)$ & 0.03 & $0.06(-0.11-0.56)$ & 0.19 \\
\hline$H D$ & $0.12(0.05-0.82)$ & 0.03 & $0.09(-0.05-0.7 I)$ & 0.09 & $0.02(-0.24-0.37)$ & 0.67 \\
\hline \multicolumn{7}{|c|}{ Linear regression CCQ symptoms } \\
\hline New HD & $0.09(-0.06-0.80)$ & 0.09 & $0.09(-0.07-0.76)$ & 0.10 & $0.05(-0.13-0.55)$ & 0.23 \\
\hline HD & $0.11(0.01-0.769)$ & 0.04 & $0.06(-0.16-0.60)$ & 0.45 & $0.00(-0.33-0.30)$ & 0.94 \\
\hline \multicolumn{7}{|c|}{ Linear regression CCQ functional state } \\
\hline New HD & $0.14(0.17-1.20)$ & 0.009 & $0.14(0.18-1.16)$ & 0.01 & $0.06(-0.11-0.72)$ & 0.15 \\
\hline HD & $0.14(0.13-1.03)$ & 0.01 & $0.12(0.04-0.92)$ & 0.03 & $0.05(-0.19-0.58)$ & 0.32 \\
\hline \multicolumn{7}{|c|}{ Linear regression CAT } \\
\hline New HD & $0.17(0.30-6.00)$ & 0.03 & $0.12(0.04-5.91)$ & 0.03 & $0.06(-0.68-3.85)$ & 0.17 \\
\hline$H D$ & $0.17(1.44-6.43)$ & 0.002 & $0.15(0.89-5.92)$ & 0.01 & $0.07(-0.40-3.76)$ & 0.11 \\
\hline \multicolumn{7}{|c|}{ Logistic regression $\mathrm{mMRC} \geq 2$} \\
\hline & OR $(95 \% \mathrm{Cl})$ & $P$-value & $\begin{array}{l}\text { OR }(95 \% \mathrm{Cl}) \text {, adjusted } \\
\text { for confounders }\end{array}$ & $P$-value & $\begin{array}{l}\text { OR }(95 \% \mathrm{Cl}) \text {, adjusted for } \\
\text { confounders and baseline mMRC }\end{array}$ & $P$-value \\
\hline New HD & $\mathrm{I} .45(0.80-2.6 \mathrm{I})$ & 0.22 & $1.37(0.74-2.53)$ & 0.32 & $0.99(0.49-1.99)$ & 0.99 \\
\hline HD & $\mathrm{I} .74(\mathrm{I} .08-2.8 \mathrm{I})$ & 0.02 & $1.71(1.03-2.86)$ & 0.04 & $\mathrm{I} .44(0.8 \mathrm{I}-2.56)$ & 0.21 \\
\hline
\end{tabular}

Notes: Results from linear regression analyses with CCQ and CAT as dependent variables. The data are presented as regression coefficients ( $\pm 95 \% \mathrm{Cl}$ ). Beside sex, only associated variables in univariate regression were included in the adjusted regression analysis: sex, age, educational level, exacerbations in the previous 6 months in 2005 and heart disease. Results from logistic regression analyses with $\mathrm{mMRC} \geq 2$ as a dependent variable. The data are represented as $\mathrm{OR}( \pm 95 \% \mathrm{Cl}$ ). Beside sex, only associated variables in unadjusted analysis were included: sex, age, exacerbations in the previous 6 months in 2005 and heart disease. The absence of heart disease (no HD) is the reference variable in all regressions with the heart disease variable. Exacerbation was defined as an unplanned health care visit or course of oral steroids in the previous 6 months at baseline. HD = COPD patients with heart disease. New HD = COPD patients who developed heart disease between 2003 and 2012 . No HD = COPD patients without heart disease.

Abbreviations: CAT, COPD Assessment Test; CCQ, Clinical COPD Questionnaire. 

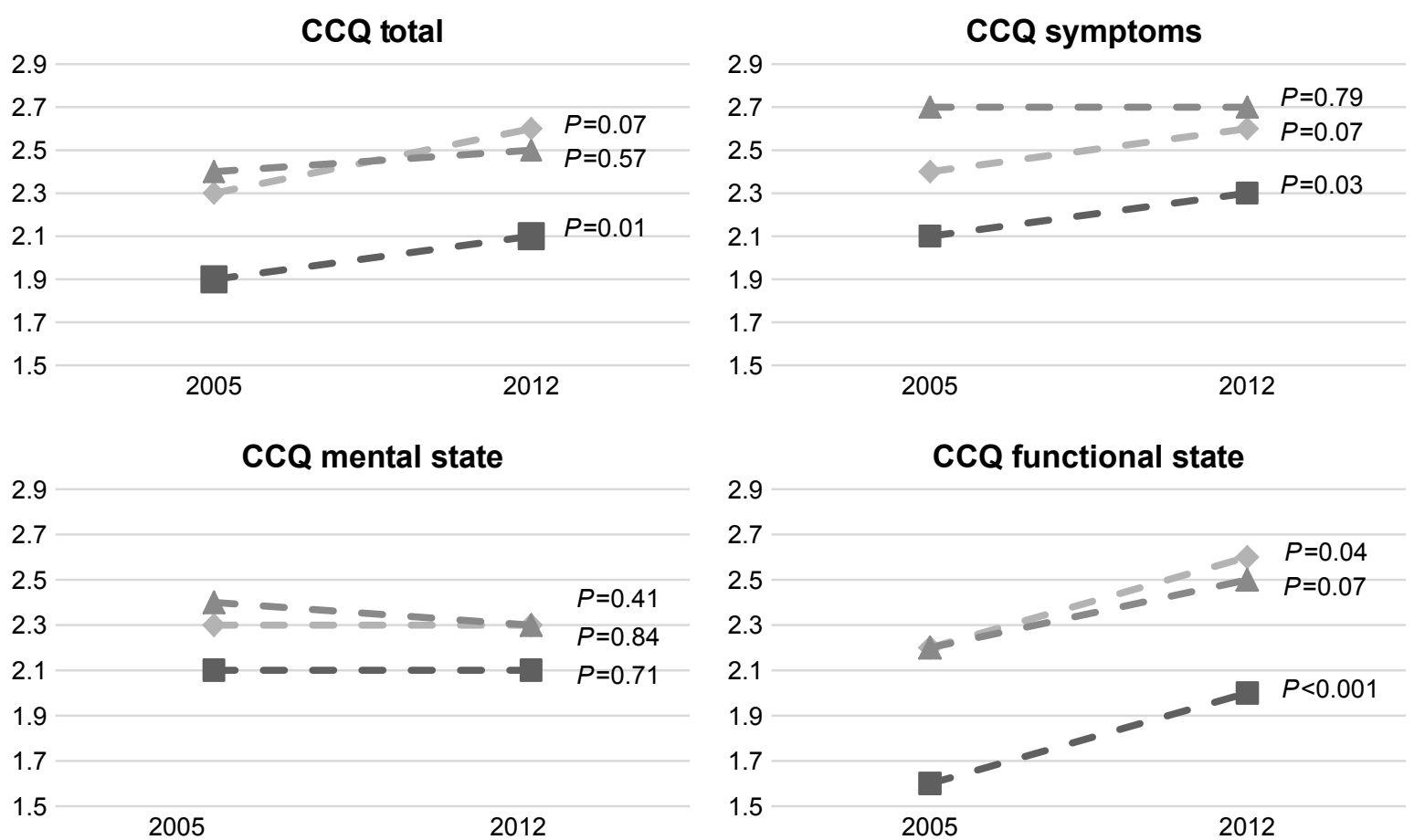

- no HD $\rightarrow-$ new HD $-\Delta-\mathrm{HD}$

Figure 4 Mean CCQ, total score and domains for 2005 and 2012 in COPD patients without heart disease (no HD), with heart disease diagnosed between 2003 and 2012 (new HD), and with heart disease at baseline (HD).

Note: $P$-values given for statistical significance of change between 2005 and 2012 value.

Abbreviation: CCQ, Clinical COPD Questionnaire.

only the association of heart disease during the whole study (HD) with CAT remained but disappeared after correction for baseline CCQ.

\section{Discussion}

The first main finding of this multicenter cohort study with 7 -year follow up is that comorbid heart disease influenced health status in patients with COPD. The second main finding is that, in COPD, dyspnea and health status worsened over time, but comorbid heart disease did not accelerate this worsening.

Our finding that comorbid heart disease influenced the patients' health status negatively has been described before in cross-sectional studies in this and other populations. ${ }^{13,22,23}$ In our study, CAT was more influenced by comorbid heart disease than the CCQ score. This has been described for this study population before. ${ }^{21}$ Health status was particularly worse for patients with HD and new HD in the CCQ functional state domain, which is consistent with a study where self-reported heart disease markedly reduced the functional state measured by 6 minutes walking distance and SGRQ.${ }^{24} \mathrm{We}$ showed in our longitudinal study that this finding remains over time and the reduced functional state can be detected by using the CCQ questionnaire.

In analysis adjusted for confounders, mMRC was not significantly influenced by new HD, whereas HD was a significant factor for higher level of dyspnea. For the CCQ total score, the opposite was found. This might indicate that comorbid heart disease in the early stages mainly reduces functionality and not symptoms.

Our finding that comorbid heart disease did not accelerate the worsening in health status and dyspnea over time is consistent with findings of the ECLIPSE study. ${ }^{25}$ The ECLIPSE study was performed over a period of 3 years on patients recruited from outpatient clinics, using self-reported heart trouble and health status assessed by SGRQ. We have expanded the findings from the ECLIPSE study as our study has a 7-year follow-up period, a patient population that is to a large extent selected in primary care and outcomes assessed by both mMRC, CAT and CCQ. This is an important finding because CAT is now mainly used for the assessment of COPD patients in daily practice.

We found a significant deterioration in health status of patients without heart disease, but not for those with a heart disease diagnosis during the whole study. The mean change 
in CCQ did not, however, exceed the minimal clinical difference of 0.4. The smaller deterioration for the HD group might be explained by regression towards the mean; Patients with heart disease already had such poor scores at baseline that worsening was less possible. Another reason could be that the care for heart disease has improved markedly in the last decade and is more structured and prioritized, which even benefits the care for comorbid COPD. It might even be possible that medication used for treating heart disease protects the lungs also. A meta-analysis of observational studies on the effect of beta-blockers on COPD outcome found that this medication reduces mortality and exacerbations in COPD patients. ${ }^{26}$ A similar meta-analysis for statins showed that statins might improve exercise tolerance, lung function, and health status in COPD patients. ${ }^{27}$

Interestingly, we found that patients who were diagnosed with heart disease later during the study showed a worse health status and symptom burden already at baseline, with a significant worsening during follow-up. This might indicate the presence of unrecognized comorbid heart disease at baseline. In this real-life study, the measure of heart disease is based on routine diagnoses rather than screening. It is known that heart disease is underdiagnosed in patients with COPD and our findings in the group with new HD suggest that this is also the case in this study population. ${ }^{9,28}$ It has previously been shown that a high SGRQ score is associated with extrapulmonary comorbidity in patients with mild to moderate air flow limitation. ${ }^{29}$ It is clinically important to be observant for heart disease and other comorbidities when there is a marked discordance between the health status scores and $\mathrm{FEV}_{1}$ \%pred in a patient.

\section{Strengths and limitations}

A major strength of this study is that the longitudinal design of this study makes it possible to identify the group of patients who develop heart disease during the study period and retrospectively look at their health status and symptoms at baseline. Another strength of this study is its generalizability to clinical practice due to its multicenter design, including patients from both primary and secondary care. The fact that that spirometry data were not available for the whole study population and patients were selected based on the doctor's diagnosis represents clinical reality in primary health care, where spirometry is not regularly repeated in the management of COPD. ${ }^{30}$

A limitation, however, is that the group with incident HD was rather small and inhomogeneous. It is unknown when exactly these patients were diagnosed during the study period and there is a 2-year period between the record review and completion of the questionnaires. Nevertheless, our results show that comorbid heart disease worsens health status in early stages, even before the clinical diagnosis.

Another limitation is that CAT was not available in 2005 and we, therefore, have no data on CAT scores at baseline. CAT is recommended by GOLD for assessment of patients with COPD, and we found it important to be able to look at this instrument and the association with heart disease over time. Prior research has found that CCQ and CAT correlate well with each other and the SGRQ, and that comorbid heart disease is associated with both instruments. ${ }^{21,31}$ The CCQ at baseline can, therefore, be a valid alternative for CAT at baseline in the logistic regression analysis.

Finally, the loss of patients during follow-up could potentially cause a selection bias. It has been shown that high CCQ scores predict mortality. ${ }^{32}$ In this study, the population with heart disease had a higher level of dyspnea and worse health status at baseline, and attrition analysis showed that the all-cause mortality was higher in this group. We cannot exclude the possibility that the absence of a longitudinal association between dyspnea and health status with comorbid heart disease is caused by the fact that patients with comorbid heart disease were overrepresented among those who died during the study period.

\section{Conclusion}

Comorbid heart disease contributes to lower health status and higher symptom burden in COPD. However, heart disease does not accelerate the worsening of symptoms and health status over time. In COPD management, it is important to optimize treatment of cardiovascular comorbidity to maintain or improve health status and to be observant for comorbid heart disease, especially when low health status and symptom burden cannot be explained by poor lung function alone.

\section{Acknowledgment}

The authors thank all participating centres, and Ulrike SpetzNyström and Eva Manell for reviewing the patient records. A part of the results of this study were presented at the Swedish National Conference for General Practitioners in April 2018 and the Congress of the International Primary Care Respiratory Group (IPCRG) in Porto in May 2018.

\section{Disclosure}

The authors report no conflicts of interest in this work. 


\section{References}

1. Halbert RJ, Natoli JL, Gano A, Badamgarav E, Buist AS, Mannino DM. Global burden of COPD: systematic review and meta-analysis. Eur Respir J. 2006;28(3):523-532.

2. Global Initiative for Chronic Obstructive Lung Disease (GOLD) [homepage on the Internet]. Global Strategy for the Diagnosis, Management and Prevention of COPD 2018. [Internet]. Available from: http:// goldcopd.org. Accessed March 20, 2018.

3. Bestall JC, Paul EA, Garrod R, Garnham R, Jones PW, Wedzicha JA. Usefulness of the Medical Research Council (MRC) dyspnoea scale as a measure of disability in patients with chronic obstructive pulmonary disease. Thorax. 1999;54(7):581-586.

4. Jones PW, Harding G, Berry P, Wiklund I, Chen WH, Kline Leidy N. Development and first validation of the COPD Assessment Test. Eur Respir J. 2009;34(3):648-654.

5. van der Molen T, Willemse BW, Schokker S, Ten Hacken NH, Postma DS, Juniper EF. Development, validity and responsiveness of the Clinical COPD Questionnaire. Health Qual Life Outcomes. 2003;1:13.

6. Chen W, Thomas J, Sadatsafavi M, Fitzgerald JM. Risk of cardiovascular comorbidity in patients with chronic obstructive pulmonary disease: a systematic review and meta-analysis. Lancet Respir Med. 2015; 3(8):631-639.

7. Putcha N, Drummond MB, Wise RA, Hansel NN. Comorbidities and chronic obstructive pulmonary disease: prevalence, influence on outcomes, and management. Semin Respir Crit Care Med. 2015;36(4): 575-591.

8. Kaszuba E, Odeberg H, Råstam L, Halling A. Heart failure and levels of other comorbidities in patients with chronic obstructive pulmonary disease in a Swedish population: a register-based study. BMC Res Notes. 2016;9:215.

9. Rutten FH, Cramer MJ, Grobbee DE, et al. Unrecognized heart failure in elderly patients with stable chronic obstructive pulmonary disease. Eur Heart J. 2005;26(18):1887-1894.

10. Van Eeden S, Leipsic J, Paul Man SF, Sin DD. The relationship between lung inflammation and cardiovascular disease. Am J Respir Crit Care Med. 2012;186(1):11-16.

11. Smith MC, Wrobel JP. Epidemiology and clinical impact of major comorbidities in patients with COPD. Int J Chron Obstruct Pulmon Dis. 2014;9:871-888.

12. Gupta N, Pinto LM, Morogan A, Bourbeau J. The COPD assessment test: a systematic review. Eur Respir J. 2014;44(4):873-884.

13. Sundh J, Ställberg B, Lisspers K, Montgomery SM, Janson C. Co-morbidity, body mass index and quality of life in COPD using the Clinical COPD Questionnaire. COPD. 2011;8(3):173-181.

14. Sundh J, Montgomery S, Hasselgren M, et al. Change in health status in COPD: a seven-year follow-up cohort study. NPJ Prim Care Respir Med. 2016;26:16073.

15. Oga T, Nishimura K, Tsukino M, Sato S, Hajiro T, Mishima M. Longitudinal deteriorations in patient reported outcomes in patients with COPD. Respir Med. 2007;101(1):146-153.

16. Spencer S, Calverley PM, Sherwood Burge P, Jones PW; ISOLDE Study Group. Inhaled Steroids in Obstructive Lung Disease. Health status deterioration in patients with chronic obstructive pulmonary disease. Am J Respir Crit Care Med. 2001;163(1):122-128.
17. Wacker ME, Hunger M, Karrasch S, et al. Health-related quality of life and chronic obstructive pulmonary disease in early stages - longitudinal results from the population-based KORA cohort in a working age population. BMC Pulm Med. 2014;14:134.

18. Standardized lung function testing. Report working party. Bull Eur Physiopathol Respir. 1983;19(Suppl 5):1-95.

19. van der Molen T, Diamant Z, Kocks JW, Tsiligianni IG. The use of health status questionnaires in the management of chronic obstructive pulmonary disease patients in clinical practice. Expert Rev Respir Med. 2014;8(4):479-491.

20. Alma $\mathrm{H}$, de Jong $\mathrm{C}$, Jelusic $\mathrm{D}$, et al. Health status instruments for patients with COPD in pulmonary rehabilitation: defining a minimal clinically important difference. NPJ Prim Care Respir Med. 2016;26:16041.

21. Sundh J, Ställberg B, Lisspers K, Kämpe M, Janson C, Montgomery S. Comparison of the COPD Assessment Test (CAT) and the Clinical COPD Questionnaire (CCQ) in a Clinical Population. COPD. 2016;13(1):57-65.

22. de Miguel-Díez J, Carrasco-Garrido P, Rejas-Gutierrez J, et al. The influence of heart disease on characteristics, quality of life, use of health resources, and costs of COPD in primary care settings. $B M C$ Cardiovasc Disord. 2010;10:8.

23. Patel ARC, Donaldson GC, Mackay AJ, Wedzicha JA, Hurst JR. The impact of ischemic heart disease on symptoms, health status, and exacerbations in patients with COPD. Chest. 2012;141(4):851-857.

24. Black-Shinn JL, Kinney GL, Wise AL, et al. Cardiovascular disease is associated with COPD severity and reduced functional status and quality of life. COPD. 2014;11(5):546-551.

25. Miller J, Edwards LD, Agustí A, et al. Comorbidity, systemic inflammation and outcomes in the ECLIPSE cohort. Respir Med. 2013; 107(9):1376-1384.

26. Du Q, Sun Y, Ding N, Lu L, Chen Y. Beta-blockers reduced the risk of mortality and exacerbation in patients with COPD: a meta-analysis of observational studies. PLoS One. 2014;9(11):e113048.

27. Zhang W, Zhang Y, Li CW, Jones P, Wang C, Fan Y. Effect of statins on COPD: a meta-analysis of randomized controlled trials. Chest. 2017;152(6):1159-1168.

28. Brekke PH, Omland T, Smith P, Søyseth V. Underdiagnosis of myocardial infarction in COPD - Cardiac Infarction Injury Score (CIIS) in patients hospitalised for COPD exacerbation. Respir Med. 2008; 102(9):1243-1247.

29. Lee H, Jhun BW, Cho J, et al. Different impacts of respiratory symptoms and comorbidities on COPD-specific health-related quality of life by COPD severity. Int J Chron Obstruct Pulmon Dis. 2017;12:3301-3310.

30. Arne M, Lisspers K, Ställberg B, et al. How often is diagnosis of COPD confirmed with spirometry? Respir Med. 2010;104(4):550-556.

31. Tsiligianni IG, van der Molen T, Moraitaki D, et al. Assessing health status in COPD. A head-to-head comparison between the COPD assessment test (CAT) and the clinical COPD questionnaire (CCQ). BMC Pulm Med. 2012;12:20.

32. Sundh J, Janson C, Lisspers K, Montgomery S, Ställberg B. Clinical COPD Questionnaire score (CCQ) and mortality. Int J Chron Obstruct Pulmon Dis. 2012;7:833-842.
International Journal of COPD

\section{Publish your work in this journal}

The International Journal of COPD is an international, peer-reviewed journal of therapeutics and pharmacology focusing on concise rapid reporting of clinical studies and reviews in COPD. Special focus is given to the pathophysiological processes underlying the disease, intervention programs, patient focused education, and self management protocols.

\section{Dovepress}

This journal is indexed on PubMed Central, MedLine and CAS. The manuscript management system is completely online and includes a very quick and fair peer-review system, which is all easy to use. Visit http://www.dovepress.com/testimonials.php to read real quotes from published authors. 